\title{
El estado natural del hombre es el Estado
}

\section{Mariano Gaudio}

\section{(2) OpenEdition}

\section{Journals}

\section{Edición electrónica}

URL: http://journals.openedition.org/ref/324

DOI: $10.4000 /$ ref.324

ISSN: 2258-014X

\section{Editor}

EuroPhilosophie Editions

Referencia electrónica

Mariano Gaudio, «El estado natural del hombre es el Estado », Revista de Estud(i)os sobre Fichte [En línea], 1 | 2010, Publicado el 14 junio 2010, consultado el 10 diciembre 2020. URL : http:// journals.openedition.org/ref/324 ; DOI : https://doi.org/10.4000/ref.324

Este documento fue generado automáticamente el 10 diciembre 2020.

(c) EuroPhilosophie 


\title{
El estado natural del hombre es el Estado
}

\author{
Mariano Gaudio
}

\section{1.}

1 En el formato del iusnaturalismo moderno el concepto de Estado se deduce de la caracterización antropológica del hombre, de las relaciones que entabla con los otros y de la tipología del contrato fundante. Las definiciones que se presentan como punto de partida resultan decisivas al momento de determinar la organización política. Las connotaciones sobre la naturaleza del sujeto (malo y orgulloso, o pacífico y trabajador, o compasivo y/o competitivo, etc.) trascienden el plano de la experiencia y, en este sentido, conciernen a la metafísica. Más allá de los posibles referentes empíricos, el estado de naturaleza se erige en la mayoría de los casos como una construcción ficcional al servicio de la fundamentación de un determinado tipo de sociedad civil o Estado. ${ }^{1}$ La artificialidad del estado de naturaleza reside en que el sujeto allí descrito, ese hombre entendido como un átomo aislado y absolutamente independiente es una abstracción, un concepto, un pensamiento.

2 A primera vista, el periplo de Fichte en el Fundamento del derecho natural a partir de los principios de la Doctrina de la Ciencia (Grundlage des Naturrechts nach Principien der Wissenschaftslehre, 1796/97) ${ }^{2}$ se podría homologar al esquema iusnaturalista, siempre y cuando se subraye que, según el proceder del método sintético, los elementos que se van descubriendo adquieren su plena significación una vez completado el círculo de implicancias. ${ }^{3}$ Muchos intérpretes (que aquí no discutiremos, prefiriendo dar lugar a la interrelación de Fichte con otros filósofos) pasan por alto este detalle y proyectan en la obra de Fichte una estructura de comprensión que no se condice con la advertencia siempre presente sobre el carácter problemático y aporético del pensamiento fichteano. Tal vez el aspecto de mayor divergencia esté precisamente en el punto de partida. Si bien es cierto que los primeros parágrafos de la argumentación parecen asentarse sobre el individuo, también es cierto que en el desarrollo se lo muestra 
vinculado en un tejido de relaciones. Análogamente, si bien es cierto que en la dimensión jurídico-política Fichte parte del derecho de propiedad y del derecho de coacción, ambas potestades de presunta legitimidad en la esfera individual terminan siendo absolutamente resignificadas en el seno de la República. ${ }^{4}$

3 Así, las dos primeras secciones del Fundamento del derecho natural, la deducción (\$§1-4) y la aplicabilidad (\$§ 5-7), se resuelven en la tercera: “Aplicación sistemática del concepto de derecho, o doctrina del derecho" (§§ 8-16). Del mismo modo, los dos primeros capítulos de la doctrina del derecho, "Deducción del derecho originario" (§§ 9-12) y "Sobre el derecho de coacción" (§ 13-15), encuentran su desenlace en el tercero: "Del derecho político, o del derecho en una República" (\$ 16). Por ende, aunque Fichte comience analizando la realización de la libertad del sujeto/individuo, de la cual deduce la necesidad de un mundo sensible limitante, ella recién adquiere sentido cuando el sujeto comprende que la propia auto-adjudicación de libertad es simultáneamente la atribución de una esfera similar a todos los otros. La subjetividad se resignifica en la intersubjetividad. La libertad infinita e indeterminada del punto de partida va ganando sentido y determinación en la medida en que se la delimita, y en la medida en que se descubre que la delimitación es, al mismo tiempo, un acto de la voluntad libre. Entonces, si se interpreta el progreso de modo lineal y unilateral, se encubre la médula problemática del planteo de Fichte, brotan las contradicciones y enigmas, se multiplican la desconexión y el fragmento. Al mostrar la determinación recíproca como la relación entre elementos que se refieren mutuamente y que, por lo tanto, no pueden existir uno sin el otro, tales elementos ya se encuentran implicados desde el comienzo, y la separación obedece al proceder del filósofo que los abstrae en busca del rasgo metafísico unificador y fundante.

4 Tomemos como ejemplo los primeros parágrafos del GNR. En el $\S 1$ Fichte define al sujeto como un ser racional finito que se atribuye una actividad libre. En el $\S 2$ establece como consecuencia que tal actividad se efectúa en un mundo sensible exterior al sujeto. En el $\S 3$ sostiene que, para adjudicarse libertad, ese sujeto debe también adjudicarla a los demás. Así presentado se podría entender que el mundo sensible y los otros sujetos se deducen como meras limitaciones de la actividad libre del individuo. Se podría entender que el punto de partida es el individuo y que todo lo demás se subordina a él. Sin embargo, en los "Corolarios" del § 3 Fichte afirma: "El hombre (esto es, todos los seres finitos en general) sólo será hombre entre los hombres". (GA I, 3, 347 GNR; FDN 133) Esto significa que el ser finito en realidad está comprendido en una pluralidad, que no hay individuos aislados, que el reconocerse como racional es al mismo tiempo un espejarse en otros seres racionales. En una palabra, el progreso sintético consiste en tomar un punto como muestra de un entramado. Ya en el $\S 3$ emerge la trabazón intersubjetiva: la adjudicación de libertad concierne a cualquier ser racional finito, es decir, a todo individuo. No significa que el otro se revele aquí como un mero obstáculo de mi actividad y, por ende, como un objeto a someter; por el contrario, mi actividad ya supone la interacción con el otro. Por lo tanto, la atribución de libertad por parte del sujeto sería imposible si éste no se realizara como tal en una comunidad. El resultado resignifica el punto de partida.

5 Algo similar ocurre, como ha de verse a continuación, entre el derecho originario, el derecho de coacción y el Estado. 


\section{2.}

Tanto el capítulo dedicado al derecho originario como el capítulo dedicado a la coacción - y que se sigue del primero - desembocan en conflictos irresolubles, donde las partes en pugna reclaman para sí derechos o posesiones con igual legitimidad. Estas aporías conducen directamente a la aniquilación del derecho, si las partes permanecen aferradas a su condición de partes en litigio. La única manera de resolver los conflictos reposa en la emergencia de un Estado capaz de valorar y juzgar sobre la situación en disputa. Pero, entonces, el Estado surgiría como una suerte de solución provisoria, un particular más, un administrador, designado como árbitro o guardián de las propiedades. Éste no es, por cierto, el caso en GNR. Fichte concibe el Estado como la unidad completa de los individuos enlazados jurídicamente. En rigor, todo el desarrollo anterior ya presupone la presencia del Estado. Ni la coacción, ni los derechos naturales, ni la comunidad de seres libres, ni el individuo mismo, existirían sin el sostén del Estado. Así, recién en su aplicación sistemática se termina de esclarecer el concepto de derecho. Analicemos, entonces, primero las aporías y luego su resolución.

7 El capítulo I de la "Doctrina del derecho" comienza con una pregunta: “De qué manera se puede pensar un derecho originario?" (GA I, 3, 403 GNR § 9; FDN 191) Fichte aclara aquí que para hablar de derechos hay que hablar de personas, lo cual significa hablar de individuos relacionados. Esto a su vez significa que los derechos no son patrimonio de los individuos por separado, sino del colectivo comunitario, porque la reivindicación de uno es al mismo tiempo la reivindicación de todos. Por lo tanto, para que se garanticen los derechos de un individuo es necesario que haya una República (ein gemeines Wesen), un ser común, una esencia o enlace que tenga el poder de hacer valer lo universal sobre lo particular. En efecto, los derechos originarios adquieren cabal sentido cuando se entablan en reciprocidad, es decir, cuando junto con la esfera de libertad de cada uno se establece la esfera de libertad de los otros y, simultáneamente una limitación recíproca entre las libertades individuales sustentada en y por una instancia supraindividual. Esta instancia que sostiene el ensamble de partes limitadas y vinculadas es el Estado. ¿Por qué, entonces, comenzar con los derechos originarios? ¿Por qué la advertencia de la abstracción, de la idealidad y formalidad del planteo? A modo de respuesta dice nuestro filósofo:

"No hay una situación [Stand] de derechos originarios, ni derechos originarios del hombre. [El hombre] tiene realmente derechos sólo en comunidad con otros [...]. Por consiguiente, un derecho originario es una mera ficción [Fiktion], pero que tiene que ser hecha necesariamente para el propósito de la ciencia." (GA I, 3, 403-404 GNR; FDN 192).

Se trata de una ficción heurística, cuyo sentido se hará manifiesto con el curso de la investigación. El derecho originario apunta a defender el ámbito de la libertad, que en la Reivindicación de la libertad de pensamiento (1793) Fichte problematiza en relación con la ley y lo proclama inalienable. ${ }^{5}$ Más allá de lo fáctico y de lo jurídico, la decisión de actuar (o de no-actuar) es, en última instancia, siempre un acto libre e intransferible. En el $\S 10$ deduce el derecho originario del concepto de libertad, y lo define, entre otros aspectos, como el derecho a ser causa primera, absoluta, sin condicionamiento. La actividad libre del sujeto se plasma en el mundo sensible a través del cuerpo, que es la expresión de la voluntad; el cuerpo se relaciona con lo dado de manera teóricacognoscente o de manera práctica-productiva, y en este último caso transforma los objetos en vista de un fin (\$11). De todos modos sabemos por la Doctrina de la Ciencia 
que teoría y práctica no son dos procesos separados y con características contrapuestas. La teoría es más bien un momento, una suerte de paréntesis de la práctica, en donde se presenta la mayor inhibición de la actividad del sujeto por parte de un objeto a conocer. Pero tal inhibición no implica la desaparición de la actividad (pues, en tal caso, se daría la desaparición del sujeto), sino tan solo su disminución, que tanto en su fundamento como en su finalidad se encuentra abrazada por una motivación de índole práctica. ${ }^{6}$

Tenemos aquí una formulación primaria del concepto de trabajo. De una u otra manera, tanto en la contemplación como en la producción, el sujeto configura el objeto y, por lo tanto, lo modifica, lo hace suyo. Incluso el sólo hecho de pensar un objeto es una manera de apropiárselo. ${ }^{7}$ Por eso Fichte presenta el trabajo como el fundamento del derecho de propiedad. Se trata de aquella parte del mundo sensible que la persona conoce y somete a sus fines. Desde luego, aclara nuestro filósofo, esta propiedad vale para la persona, no para la sociedad; pues aún estamos en el terreno de lo individualproblemático. Y considera que ha resuelto la polémica entre dos posiciones sobre el fundamento del derecho de propiedad: la formación o actividad sobre la cosa y la mera voluntad de posesión. La polémica, dice,

“...está resuelta mediante la conciliación sintética de ambas opiniones, como no podía ocurrir de otro modo en un sistema que procede estrictamente según el método sintético". (GA I, 3, 407 GNR; FDN 196; el subrayado es nuestro)

Porque la no-modificación de una cosa es, asimismo, una modificación. En ambos casos se presenta una subordinación de la cosa a los fines de la persona. Porque conocer o dejar ser a la cosa también forman parte del querer.

11 Ahora bien, estas consideraciones abstractas sobre el derecho de propiedad versan sobre el concepto de fin, que a su vez presupone un estado futuro. La persona no sólo quiere conservar su vida, no sólo quiere someter las cosas a sus fines, sino que también quiere la permanencia de esta situación. Al extenderse más allá del presente, la voluntad envuelve un futuro, lo implica, lo determina. De ello se desprende que la apropiación trae consigo un reclamo a priori: el reconocimiento del derecho de propiedad; es decir, la garantía de que tal derecho será respetado por los otros. Sin embargo, se pide aquí lo que no se da: si originariamente la apropiación es infinita (y presentada la libertad en la condición individual no hay ningún motivo para que no lo sea), ¿por qué hemos de esperar una limitación de la misma?

Por lo tanto, si se examina el pasaje del derecho originario al derecho de coacción (§ 12) de manera lineal, sin reparar en la metamorfosis intrínseca del planteo, se diría que el gesto mismo de apropiación implica la exigencia según la cual los otros (hasta ahora, ausentes) quedan excluidos y deben abstenerse de extender sus intereses sobre tales o cuales cosas. En tal perspectiva, si un ser libre atenta contra la propiedad de otro, éste tendría derecho de reclamar por aquello que considera suyo. La superficialidad del análisis se completaría del siguiente modo: como cualquier persona comprende que lo suyo excluye a los demás, debe aceptar que al apropiarse de algo renuncia a lo propio de los demás. Es como pedir que la libertad infinita devenga mágicamente autolimitada. En efecto, cualquiera podría comprender que la extensión ilimitada de la libertad genera conflicto y, por ende, que se requiere de una distribución, de una cantidad razonable para cada uno, de un "derecho igual para todos" o de un "equilibrio del derecho". (GA I, 3, 410 GNR; FDN 199) Pero con ello se le pide a la persona que abandone la lógica egoísta que sacraliza la propiedad privada y rechaza de plano toda limitación, y se entregue a una lógica abnegada donde cada uno se conforma con lo suyo y 
prescinde de sus posibilidades de expansión. Y aun cuando se pudiera convencer a las partes en litigio de que deben autolimitarse para, por ejemplo, garantizar la conservación de lo propio y establecerlo mediante la ley jurídica, la delimitación recíproca permanecerá siempre en el plano formal y problemático, puesto que "es un concepto vacío, incapaz de alguna aplicación". (GA I, 3, 411; FDN 200) Y aunque se lleve a cabo una declaración o explicitación de las posesiones de cada uno, no hay manera de resolver cuál de las partes en pugna realizó primero la apropiación de una cosa en litigio y, en consecuencia, surge entre ellas

"un conflicto jurídico que no se puede decidir, y un conflicto entre fuerzas físicas que sólo puede finalizar con la aniquilación física o con la expulsión total de una de las dos [partes]." (GA I, 3, 415 GNR; FDN 203)

Cabe aclarar que Fichte no se empantana en la superficialidad del planteo, porque llega a esta conclusión escéptica descartando una y otra vez un posible acuerdo, esto es, descartando que se puedan distribuir cuantitativamente las posesiones, o que se pueda determinar quién se apropió primero de la cosa en cuestión, o que se alcance una resolución que deje conforme a las partes en pugna. Cualquiera de estos acuerdos no tienen ningún sustento jurídico ni viso de factibilidad, están condenados a perecer desde su surgimiento. En última instancia, la armonía social preestablecida soslaya la necesidad del derecho y de la política; y la pretensión de deducir una dinámica colectiva de la actividad individual o, de modo equivalente, de convertir la prosecución del interés egoísta en el progreso del conjunto, se revelan como alternativas formales, parciales, insuficientes para un planteo profundo. El conflicto jurídico requiere de una resolución definitiva, de lo contrario, su desencadenante es la guerra y la aniquilación de una de las partes. En una palabra, el derecho originario conduce al Estado.

14 La especulación de Fichte condensa una estela lockeana con un trasfondo hobbesiano. Por un lado, como en el estado de naturaleza no es posible llegar a un acuerdo en caso de litigio, las partes comprenderían que el mejor modo de asegurar la posesión efectiva de sus bienes frente a toda posible usurpación consiste en nombrar a un tercero, el cual se reservaría la capacidad de decisión, tanto respecto de la valoración jurídica como respecto de la garantía de cumplimiento de la misma. Las partes,

"por ende, tienen que subordinar a este tercero su derecho a juzgar y su potencia

física. Esto significa, según lo anterior, que tienen que unirse unos con otros en una República [gemeines Wesen]." (GA I, 3, 417 GNR; FDN 206).

En apariencia la República subsana el problema de la propiedad. Sin embargo, unas líneas más abajo Fichte sostiene que "toda propiedad se fundamenta en la unión de la voluntad de muchos en una única voluntad.” (GA I, 3, 417 GNR; FDN 207) En rigor, no hay propiedad sin reconocimiento recíproco. La propiedad no se agota en la mera voluntad de poseer algo. Afinando los conceptos, una posesión deviene propiedad cuando es reconocida por otros y adquiere validez jurídica. Pero el reconocimiento recíproco padece las mismas limitaciones propias de la subjetividad: siempre hay un otro que no ha entrado o sido incluido aún en ese tejido. Entonces, para asegurarse una posesión, debería buscarse el reconocimiento de la humanidad entera:

"Asegurarse este reconocimiento parece una inmensa tarea, y sin embargo es fácil de resolver y está resuelto en la realidad desde mucho tiempo por la constitución actual de los hombres. A cada uno que viva en una República, ésta le reconoce y garantiza su propiedad [...]. A ésta [la República], [es decir] al Estado, los Estados limítrofes le reconocen su propiedad, esto es, la propiedad de cada uno de los ciudadanos." (GA I, 3, 418; FDN 207) 
Por otro lado, en sentido estricto sin Estado no hay propiedad alguna. Si éste se limitase a reconocer y asegurar las posesiones previamente existentes, predominaría la línea de Locke: habría que reconocer algo fuera o anterior al Estado. ${ }^{8}$ Sin embargo, tales posesiones se vuelven ilusorias de no haber un poder común que las sustente. Fichte no está diciendo - ni, mucho menos, va a decir - que el Estado surge para resolver el problema de la propiedad; más bien dice y dirá, en sintonía con Hobbes, que únicamente puede haber propiedad en el Estado. ${ }^{9}$ Son dos cosas muy diferentes. Por lo tanto, no existe la propiedad anterior al Estado, sino que, porque existe el Estado, existe la propiedad. De la misma manera que no existe el individuo aislado, sino en interrelación con los otros. La unidad se revela como la instancia de constitución y de sentido de cada una de sus partes componentes.

\section{3.}

17 Al avanzar hacia el derecho de coacción Fichte retoma y refuerza el carácter problemático de su procedimiento: no hay ninguna garantía ni seguridad de que los seres racionales se sometan a la ley jurídica. Por ende, lo que se debe demostrar, esto es, el sometimiento a la ley, pasa a ser un presupuesto. $Y$, como bien señala, de este punto depende todo el planteo. (cf. GA I, 3, 424 GNR § 13; FDN 213-214) La única manera de lograr seguridad recíproca en el sometimiento a la ley, más allá de la confianza y la buena fe que sólo resuelven el problema en el plano moral, consiste en identificar la ley jurídica con la voluntad, de modo que el mandato de la voluntad sea el mandato del derecho, y el querer de cada uno el querer de la ley. Ninguna convención, ningún pacto, ninguna promesa, ninguna fraternidad, pueden sustituir a ese mecanismo que está articulado, en la teoría, con una necesidad férrea. Precisamente la ley de coacción es un dispositivo (Veranstaltung) que convertiría a toda acción contraria al derecho en una acción contraria a la voluntad. (cf. GA I, 3, 427 GNR § 14; FDN 217)

18 Ahora bien, la voluntad humana se pone a sí misma fines, de los cuales desprende los medios subordinados a tales fines, con absoluta libertad. Por lo tanto, no se la puede reducir a un operar mecánico. Se presenta aquí un dilema insalvable: la seguridad recíproca y la libertad son inversamente proporcionales. Para que un procedimiento coactivo funcione infaliblemente hay que presuponer seres de voluntad mecánica, lo cual es imposible: o los seres tienen voluntad y entonces el mecanismo nunca garantiza seguridad plena; o el dispositivo funciona y los seres no son libres y racionales. Para superar esta contradicción, la libertad y la seguridad recíproca que limita a la primera tienen que reunirse sintéticamente. Esto significa traducir la violación de los derechos del otro en una violación de los propios derechos de uno. (cf. GA I, 3, 429 GNR; FDN 219) Dado que los límites son constitutivos del sí-mismo (y no un mero cerco para que el otro se contenga de hacer uso de lo mío), en el simple vínculo y en la simple limitación queda involucrada toda la comunidad. La simetría y la intercambiabilidad de funciones son medulares en este planteo de reciprocidad que envuelve a todos los sí-mismos y a todos los otros.

19 Pero Fichte prosigue su exposición en la línea de Locke: para cumplir con la ley de coacción, es necesario un poder (Macht) que funcione como el mecanismo indicado. Y se pregunta: “PPor quién debe ser instaurado, ante todo, un poder semejante?” (GA I, 3, 430 GNR § 15; FDN 220) ${ }^{10}$ Esta pregunta desnuda las falencias del contractualismo. Aquellos que han de instaurar un poder que los coaccione tienen que razonar desde el 
nivel de lo universal, cuando la lógica que los convencería para realizar tal engendro debería circunscribirse a lo particular. Dicho rápidamente, se les exige que piensen como ciudadanos cuando todavía no lo son. Entonces, la pregunta se vuelve retórica si ese "quién" debe recibir una respuesta despersonalizada. Se supone, siguiendo la exposición de Fichte, que el poder coactivo es un medio necesario para alcanzar un fin deseado (la seguridad recíproca), y quien quiere los fines, también debe querer los medios. Desde luego, no se trata de un fin cualquiera, sino de un fin deseado necesariamente; con lo cual, el mecanismo coactivo se revela como anterior. De esta manera, quienes no quieren reconocer que un poder coactivo es a priori condición de toda sociedad, quedan afuera de la sociedad contrayente.

Hasta aquí, proyectando hipotéticamente los elementos disponibles, el Estado parecería estrecharse como un mero producto para solventar la convivencia pacífica de los individuos; es decir, como un remiendo para las fracturas de la confianza y de la buena fe entre los individuos. No obstante, en apenas unas líneas Fichte cambia de registro y escribe:
“Ahora bien, ¿cuál debe ser este poder? Este poder es dirigido por un concepto, y se atiene a la realización de un concepto, el cual, por cierto, es elaborado con libertad absoluta, a saber, el de los límites que ambos [contrayentes] han puesto en el contrato a sus acciones [ihrer Wirksamkeit] en el mundo sensible. Por ende, no puede ser un poder mecánico, sino que tiene que ser un poder libre. Ahora bien, un poder semejante, que reúna en sí todas estas exigencias, no es puesto en absoluto fuera de su propio poder determinado por su voluntad común." (GA I, 3, 430 GNR; FDN 220; subrayado nuestro)

21 El asunto cobra otra dimensión. El poder soberano obedece a un concepto cuyo fundamento es la libertad absoluta, que ya no se restringe a la extensión de la libertad de un individuo, sino que absorbe en unidad todos los límites que la coacción solicita. En esta concepción metafísica y política, el Estado no consiste en un dispositivo mecánico encargado de reparar las asperezas y administrar la usual armonía de la comunidad; sino que es un poder libre, que se fundamenta en la libertad y que no queda supeditado al entendimiento subjetivo. Por eso, no es algo puesto, aunque claramente su poder efectivo no proviene del más allá, sino de la voluntad universal, o sea, de su propio querer, el cual concilia a las partículas y sus limitaciones en una totalidad. En su concepto, el poder soberano se determina y pone a sí mismo.

Una vez más, el contractualismo naufraga en el rompecabezas de la subjetividad conflictiva, si no prima la unidad sobre los múltiples fragmentos. En el derecho de coacción las partes vuelven a marcarse por su carácter incompleto: la designación de roles para dos individuos en conflicto (agresor y agredido) empalma con una serie de dilemas si uno de ellos se auto-adjudica el poder de coacción. De por sí, los roles no quedan muy bien definidos, porque el agresor podría alegar una justa causa, y entonces agresor y agredido se alternan sucesivamente. Nada garantiza - razona Fichte, en la tesitura de la objeción lockeana de la imposibilidad de ser juez y parte - que no haya exceso o error en el castigo; porque todos tienen razones $y$, en cuanto partes interesadas, no van a abandonar su lógica de justificación. En última instancia, un contrato restringido a los términos de la particularidad sólo se podría cumplir en favor de los más poderosos, que son quienes efectivamente pueden castigar con justicia o sin ella. Por lo tanto, la única manera de resolver las contradicciones escépticas y paralizantes (porque, por ejemplo, la discusiones sobre los derechos de uno y de otro, o sobre los roles agresor/agredido, o sobre la dimensión de la pena, se extienden 
indefinidamente) de la coacción consiste en igualar poder (Gewalt) y derecho. Para que no haya individuos más poderosos que otros ni se consagre la definición de justicia de Trasímaco o el pacto injusto según Rousseau, ${ }^{11}$ es absolutamente necesario establecer un poder supremo como fundamento de la igualdad de derechos. Recién entonces se podrá hablar de propiedad, de coacción y de justicia. ${ }^{12}$

El derecho originario y el derecho de coacción coinciden al menos en dos puntos centrales: la naturaleza problemática de los planteos respectivos y la resolución de esas lagunas en un poder supremo. Las categorías fundantes del contractualismo (estado de naturaleza y contrato) quedan subsumidas al tercer momento. La libertad absoluta que extiende posesiones y la limitación recíproca en aras de la seguridad sólo tienen sentido, validez y aplicación, en el seno de una República. Sólo si hay un poder soberano capaz de garantizar la posición de cada parte y la armonía del todo, es posible conciliar la libertad con el sometimiento a la ley. Consideradas por separado y fuera del Estado, la apropiación y la coacción resultan en sí mismas inconsistentes y absolutamente incompatibles; su funcionamiento es siempre provisorio y contingente, supeditado a la bondad moral de los litigantes o convivientes. Concluye Fichte:

"Por consiguiente, no existe en absoluto un derecho natural, en el sentido en que habitualmente se ha tomado el término; esto significa: no existe ninguna relación jurídica entre los hombres fuera de una República y bajo leyes positivas [...].

Pero lo que perdemos por un lado, lo recuperamos por el otro, con ganancias; porque el Estado mismo se convierte en el estado natural del hombre, y sus leyes no deben ser otras que el derecho natural realizado." (GA I, 3, 432; FDN 222). ${ }^{13}$

24 Así, las elucubraciones relativas a los individuos y sus relaciones flotan sobre el vacío y la abstracción. Esas ficciones se apuntalan en la República, donde lo hipotético y problemático se torna certero y asertórico; pero no se trata de un condicionamiento, sino de un remontarse hasta la condición: recién con el concepto de una República el derecho originario y el de coacción alcanzan su justeza, su verdadera dimensión. En la medida en que el Estado encarna el concepto de derecho, las reivindicaciones de libertad e igualdad, propiedad y seguridad, autonomía y vínculo, etc., adquieren sentido $\mathrm{y}$ aplicación. Pero fuera del Estado no hay derecho alguno y, por ende, no hay racionalidad, porque las relaciones que se puedan entablar no se perfilan bajo el reconocimiento de la igualdad de las partes, sino bajo el signo de la fuerza. Son relaciones endebles, que conllevan en sí el germen de su destrucción y, por decirlo de alguna manera, que se retuercen hasta realizar la igualdad y la libertad que caracterizan a las relaciones jurídicas.

\section{4.}

Tras entramparse en las aporías del derecho originario y del derecho de coacción, Fichte vuelve a recoger en el capítulo III, § 16 de GNR, titulado "Deducción del concepto de una República", el camino transitado, enfatizando precisamente que el nudo irresoluble alcanza su culminación con el concepto de Estado. Es decir, aquello que se presentaba como problemático en la situación no-estatal ficcionalizada, gana necesidad resolutiva al realizarse el concepto de derecho en una potencia soberana, la República. ${ }^{14}$ Pero semejante concepto conlleva un posicionamiento diferente de la subjetividad en relación con la instancia universal. Examinemos los primeros pasos, indicados en números romanos, que da Fichte en este parágrafo: 
(I) Lo que hasta ahora unificó el querer de los individuos fue la seguridad recíproca. En este momento lockeano, uno quiere la seguridad del otro porque quiere su propia seguridad; o sea: "Cada uno subordina el fin común a su fin privado." (GA I, 3, 433; FDN 223). ${ }^{15}$ De ser así, la voluntad común pasa a estar sometida por la voluntad particular, exactamente al revés de lo que se buscaba; de ser así, el sujeto se sobrepone y aniquila la independencia del Estado. La respuesta de Fichte es un tanto extraña, y quizás apele a una eticidad previa a los enlaces jurídicos: la subordinación de la voluntad particular y la concordancia recíproca en un fin común no tienen que ser producidas, pues en este caso - aclaremos - los sujetos se arrogarán una potestad por encima del poder soberano, sino que tienen que existir. Las impugnaciones del estado de naturaleza y del individuo-átomo juegan a favor de una tesitura que decodifica lo común como algo intrínseco a la subjetividad, convirtiendo al particularismo en una deformación de la unidad de pertenencia. No se trata, entonces, de forzar el planteo como si hubiera una voluntad unificadora, extrínseca, surgida del aporte siempre reacio de individuos que sólo quieren proteger lo suyo; sino de remontar lo particular a una dimensión vinculante que resignifica al individuo en su posición en el todo.

(II) En este sentido, la tarea del derecho político y de toda la filosofía del derecho consiste en "encontrar una voluntad para la cual sea absolutamente imposible ser otra que la voluntad común", o "una voluntad en la cual la voluntad privada y la común estén sintéticamente unificadas". (GA I, 3, 433 GNR; FDN 224) Suponiendo que el anclaje de lo comunitario esté en lo particular: ¿cómo se transforma ese querer egoísta, basado en la conservación de sí, en un querer universal y necesario? Se podría responder lo siguiente: las perspectivas de cada uno de los sujetos que desean asegurar su vida convergen en un mismo punto, y sólo en este mismo punto concuerdan todos. Así, al modo de una mano invisible, se produciría una mágica reversión del individualismo en causa común. No es el caso de Fichte, porque desconfía de esta lógica endeble y funcional al ámbito privado, donde la convergencia resulta ser nominal, una mera excusa o mal trago para seguir defendiendo el propio interés.

(III) De allí que entonces plantee lo siguiente:

"Pero semejante concordancia es un mero concepto, que no debe permanecer [como tal], sino que debe ser realizada en el mundo sensible, esto es, debe ser establecida en una expresión determinada y operar como fuerza física." (GA I, 3, 434 GNR; FDN 224)

No basta con acordar en un mismo punto, ni con reconocer esta coincidencia en el pensamiento; no basta con exponer un concepto y asignar administraciones. La unidad no es un producto, sino un hallazgo de la razón, que debe concretizarse, ganar cuerpo y volumen, y constituirse como expresión de la actividad comunitaria. Por lo tanto, no puede quedarse en el plano de la idealidad, como una utopía inalcanzable. ${ }^{16} \mathrm{La}$ expresión materializa un significado; así como el primer principio de la Doctrina de la Ciencia expresa la actividad que se genera a sí misma (Thathandlung), (cf. GA I, 2, 255 GWL § 1; FDC 13) o como el Verbo (Logos) deviene carne, (GA I, 9, 118-119 ASL, DRel 110) la expresión es el cruce donde lo ideal y lo real se concilian. Esa unidad pensada adquiere una dimensión y exteriorización concretas en el Estado. Éste es el tema a dilucidar, y sin embargo Fichte se desvía hacia una serie de requisitos adyacentes y aclaratorios, demasiado calibrados hacia lo empírico: (a) una determinada cantidad de hombres, en un determinado tiempo y lugar, se dicen unos a otros que quieren vivir juntos, y elaboran un contrato de ciudadanía; (b) se requiere que esa voluntad común sea constante y duradera, que devenga ley; (c) que determine derechos (legislación 
civil) y castigos (legislación penal); (d) y que se provea y ejecute el poder soberano, el poder político o del Estado, que reúne en sí el poder ejecutivo y el judicial.

Ahora bien, la concordancia entre particulares no involucra solamente el interés, sino algo más profundo y comprometedor: el propio querer. Algo propio que, en verdad, se construye a través del reconocimiento con el otro $\mathrm{y}$, por lo tanto, no es patrimonio ni mérito exclusivo del individuo. En este sentido, se modifica sustancialmente la matriz que sobrepone el sujeto a la unidad. El pacto y el estado de naturaleza suelen funcionar como categorías que subliman la voluntad particular sobre la voluntad común. Cuando Fichte se pregunta por la autoconservación del poder soberano (IV), no presenta a la voluntad particular y privada como si fuera ajena o independiente de la común, porque dice: "El poder de todos [...] contiene el poder de cada individuo en los limites de cada individuo". (GA I, 3, 435 GNR; FDN 226) Es que el poder soberano comprende y delimita la esfera de cada uno; en efecto, si alguien transgrede ese límite, queda fuera de la ley y fuera de la totalidad, por lo cual: "Su voluntad ya no concuerda con la voluntad común, sino que se convierte en voluntad privada." (Ibíd.) Entonces, una voluntad deviene privada cuando rompe su inserción orgánica en el todo y se pone como si estuviera afuera. En un litigio, las partes se convierten - valga la redundancia - en particulares, es decir, se separan de la totalidad. Y el conflicto se puede superar sólo dentro de la unidad estatal, porque quedó claro que, cuando se lo plantea fuera del Estado, se diluye en irresolución o, lo que es equivalente, se multiplica en una guerra indefinida. Así, la lógica liberal representa más una ruptura o escisión con la dimensión comunitaria de pertenencia que su fundamentación. Sin unidad de contención, lo particular se destruye a sí mismo. Como veremos, los límites conciernen a algo más profundo que las medidas policíaco-represivas: el apuntalamiento de los componentes sociales.

31 (V) Igualmente, siempre cabe la posibilidad de que el poder soberano se degenere en voluntad privada y por preferencia, o por beneficio, o también por error, promueva una sentencia injusta, asociándose con - es decir, particularizándose en - el interés de uno de los litigantes. Esta premisa rousseauniana cobra asidero cuando la complicidad se entabla entre poderosos que, invistiéndose de presunta legitimidad jurídica, buscan oprimir a los débiles. Fichte objeta de raíz semejante consagración de la injusticia: si los detentores del poder soberano se rebajan a intereses particulares, no están ejecutando la voluntad común, sino sólo la voluntad de un determinado sector social; por ende, se anulan las relaciones jurídicas. ${ }^{17}$ Todas sus promulgaciones carecen de fuerza de ley, carecen de universalidad. Se podrían aplicar sólo al sector del cual emanan. Admitirlas como leyes significaría admitir la injusticia como principio jurídico, lo cual es absurdo. Y, puesto que de un acto injusto (realizado o resultante por omisión) se desprende la habilitación para actos similares, ese solo hecho desencadena la resistencia y es el puntapié de la guerra de todos contra todos y de la auto-destrucción de la República.

El problema no se centra tanto en el momento fundacional, que o bien incluye en condiciones de igualdad o bien excluye - $\mathrm{y}$ entonces quienes buscaban atribuirse ciertas prerrogativas deben quedar afuera de la comunidad -, sino más bien en lo que podría llamarse el devenir natural de los acontecimientos. Uno de los motivos más antiliberales de Fichte se manifiesta aquí, en la feroz condena a la inoperancia del Estado. De la misma manera como un solo acto injusto genera una serie de actos similares, si el poder soberano omite castigar un delito promueve un terreno fértil para su proliferación. En efecto, la vida del Estado reside en la actividad, en la capacidad de intervenir a cada momento sobre el tejido de relaciones. ${ }^{18}$ Aunque parezca referirse 
específicamente al poder de policía o al judicial - insistimos - Fichte extenderá la omnipresencia del Estado hasta el espacio más sagrado del liberalismo, la economía. Dado que lo público a la vez que limita, entrelaza y atraviesa las esferas particulares, resulta absurdo defender a éstas como si fueran separadas e independientes del Estado, tan absurdo como reintroducir el irresoluble y anárquico estado de naturaleza. El límite, que cualquier liberal acordaría como defensa de lo propio, es al mismo tiempo vínculo recíproco que moldea a los elementos implicados.

Los siguientes pasos de la reflexión del $§ 16$ presentan una serie de consideraciones (VI: la transferencia del poder político al ejecutivo, los sistemas de gobierno; VII: la elección y las características de los miembros del gobierno; VIII: la limitación del poder ejecutivo, IX: el retorno de la soberanía al pueblo en casos especiales, el papel del eforato, etc.) que, por cuestiones de espacio, dejamos de lado, para concentrarnos en el aspecto que venimos anticipando y en la resignificación de los conceptos de propiedad y seguridad.

5.

En la segunda parte de GNR, publicada en 1797, Fichte se ocupa nuevamente del "Derecho político", subdividido en tres secciones: la primera trata sobre "el contrato de ciudadanía" (§ 17), la segunda sobre la "legislación civil" (\$§ 18-20) y la tercera sobre "la constitución" ( $\$ 21)$. Como al comienzo de la tercera sección aclara que los aspectos fundamentales de la constitución ya han sido expuestos, y que en adelante sólo se atendrá a determinaciones empíricas y contingentes (GA I, 4, 80 GNR; FDN 337), nos apartamos del § $21 \mathrm{y}$ analizamos los anteriores.

En el contrato de ciudadanía (\$17) el problema a dilucidar es la unión que subsume y transforma las distintas voluntades particulares y sus perspectivas (contradictorias) de propiedad y seguridad. Por más que logren establecerse acuerdos recíprocos entre lo que pertenece a uno y lo que pertenece a otro, en ausencia del Estado todos los pactos resultan problemáticos y nada garantiza el respeto de los límites. Pero la cuestión a resolver en este punto se podría formular así: ¿cómo, o por qué, los individuos que vienen razonando en función de sí mismos, de pronto concuerdan en orientarse en función de lo común? Si la voluntad particular se caracteriza por la circunscripción a su propia esfera, ¿cómo es posible que de un conjunto de voluntades constituidas de esa manera surja una voluntad común? La clave reside en encontrar el vínculo orgánico que revele al individuo no como un todo cerrado sobre sí mismo y separado de los demás, sino como parte de una totalidad, como miembro de un tejido de relaciones recíprocas. Examinemos cuidadosamente este movimiento argumentativo.

Al momento de reclamar protección, plantea Fichte, ¿para quién, a quién o contra quién se la reclama? En rigor, para ninguno en particular, o para todos. Las relaciones recíprocas no sólo vinculan a un individuo determinado con otro individuo determinado, y así sucesivamente, sino también a cada uno con cada uno, de modo que cualquiera está relacionado con cualquiera; es decir, todos los puntos se interconectan:

"el concepto de lo que hay que proteger en general se halla en un oscilar [ist im Schweben]: es un concepto indeterminado; y ciertamente de ahí surge el concepto de un todo no meramente imaginado, [...] sino el concepto de un todo real, que está reunido por la cosa misma; no [es el concepto] de meramente todos [Aller], sino de una totalidad [Allheit]." (GA I, 4, 13 GNR; FDN 266) 
es el momento donde lo que parecía un espacio vacío empieza a espacio vital. Al suspenderse y fluctuar sobre los diversos puntos, la imaginación los conecta entre sí, pero no como un simple producto del pensamiento, no como un concepto abstracto que no alcanza a determinar todos sus puntos, sino como una unidad cualitativa donde los puntos van a tener significación en base a la totalidad que los constituye. ${ }^{19}$ Lo dice Fichte claramente: no se trata de un compositum donde las partes se van agregando, sino de un totum donde las partes se articulan entre sí:

“este oscilar de la imaginación es el vínculo orgánico [Vereinigungsband]. Es aquello mediante lo cual todos confluyen en uno, y están reunidos ya no en un concepto abstracto, como un compositum, sino en los hechos, como un totum. Así, la naturaleza recompone en el Estado lo que [ella misma] separó en la generación de múltiples individuos." (GA I, 4, 14 GNR; FDN 267) ${ }^{20}$

La organicidad se justifica con el siguiente ejemplo metafórico de Fichte: el árbol, que es un "producto organizado de la naturaleza", territorialmente arraigado, comprende una cantidad de partes, que si se las dotara de conciencia y voluntad, captarían que su propia autoconservación depende de la conservación del todo. De igual modo, el daño sufrido por una de ellas sería compartido por las restantes. No sucede lo mismo con la arena, dice nuestro filósofo, porque allí cada partícula es independiente e indiferente de las demás. En este sentido, en la República no hay voluntad privada propiamente dicha, sino ante todo voluntad común, (cf. GA I, 4, 14 GNR; FDN 267) de la cual la primera es un desprendimiento que, o bien actúa en coherencia, o bien se quiebra y deviene particular.

Sin embargo, en el contrato de reunión el individuo no se entrega por entero, sino tan solo parcialmente. ${ }^{21}$ En este aspecto Fichte pareciera volver a la línea de Locke y distanciarse de Rousseau y de Hobbes. La contribución que se le exige al individuo para formar parte del Estado, el darse a sí mismo y sus cosas, no es completo. ¿Por qué? ¿Por qué Fichte se opone a la entrega incondicionada que pregona Rousseau? Él mismo se encarga de aclararlo, en nota al pie de página:

"Rousseau admite un derecho de propiedad anterior al contrato estatal y fundado en la formación [de las cosas]. Entonces, es natural que cada uno tenga que negociar con los restantes esta propiedad suya, y que pueda llegar a ser su propiedad sólo porque en el Estado le es reconocida su posesión; y que, por ende, ella esté sometida a la decisión de la voluntad común [...]. En este sentido, sin dudas cada uno daría todo.

Según nuestra teoría, en un contrato de ciudadanía nadie puede aportar algo y darlo, porque antes de este contrato no tiene nada." (GA I, 4, 15 GNR; FDN 268)22

Por lo tanto, no existe la propiedad anterior al Estado. Este giro argumentativo es fundamental. Claramente, si se estableciese un derecho natural de propiedad basado en la actividad humana, en el trabajo, Fichte aceptaría que todos tengan que entregar todo al Estado para que éste lo redistribuya equitativamente, según la decisión de la voluntad general. Pero en este esquema se cuelan suspicacias particulares sobre el aporte y el reparto, interfiere el cálculo utilitario, que Rousseau consuela mostrando las ventajas o ganancias de ingresar al cuerpo social, y en última instancia siempre queda el resabio de que por encima del Estado opera la subjetividad. Fichte corta de raíz el asunto, despojando por completo al individuo de posibles prerrogativas.

41 Cabe entonces aclarar que el concepto de propiedad resulta muy ambiguo. Por un lado, en efecto incluye los bienes que el trabajador considera suyos (por ejemplo, la tierra y la vivienda); por otro lado, refiere específicamente a su actividad. (cf. GA I, 4, 8 GNR; 
FDN 260) Probablemente sea este último sentido el que a Fichte le preocupa no enajenar por completo, dado que en tal caso no habría ningún espacio de libertad a nivel individual. Así, la contribución refiere al impuesto, es decir, a una porción de actividad que todo ciudadano debe aportar para el sostenimiento del Estado. Estas dos acepciones de la propiedad aparecen aquí como entremezcladas:

“[E]l todo es propietario de toda posesión y de los derechos de todos los individuos, en donde todo perjuicio de éstos se considera y se tiene que considerar como ocasionado a él mismo; pero, en la medida en que se considera algo como sometido a su libre uso, la propiedad del Estado es sólo lo que cada individuo adeuda contribuir." (GA I, 4, 17 GNR; FDN 269)

42 Como el Estado no tiene que reconocer posesiones previas, sino más bien expresar y ejercer su soberanía en un determinado territorio y repartir la propiedad igualitariamente entre sus miembros, primero da y luego exige un impuesto, que de ser total ahogaría el trabajo de los sujetos. Al no reconocer la apropiación como un gesto individual, Fichte se desembaraza de los lineamientos liberales y sitúa la prioridad del todo en su justo lugar, no ya como un mero recurso utilitario - en el sentido de que conviene abonar un poder fuerte para asegurar mayor protección -, sino como la unidad que posiciona a cada elemento en su lugar. Esto no significa que los individuos se reduzcan a la condición de instrumentos de la maquinaria estatal y todo lo que hagan deba contribuirse al Estado, porque en tal caso junto con la realización del derecho se daría al mismo tiempo la aniquilación de la libertad, lo cual es contradictorio. La totalidad social abraza a todos sus miembros y absorbe de ellos una porción de su actividad, no su vida entera.

6.

43 El organicismo se acentúa en el "Corolario" del § 17, donde Fichte retoma la distinción entre el concepto abstracto del todo surgido de la compilación ideal de individuos, del verdadero concepto encarnado que revela la necesaria conciliación de los elementos implicados. La imagen que mejor ilustra este último concepto es la del "producto organizado de la naturaleza", con la cual - según nuestro filósofo - se ha buscado mostrar la unidad de las ramas del poder público, pero que aquí se aplica por primera vez a las relaciones sociales en su conjunto:

"Al igual que en un producto de la naturaleza, cada parte puede ser lo que es sólo en este vínculo [Verbindung], y fuera de este vínculo no existiría en absoluto; pues fuera de todo vínculo orgánico no habría absolutamente nada [...]; asimismo, sólo en el vínculo con el Estado el hombre recibe un estamento [Stand] determinado en la serie de las cosas, un punto de apoyo [Ruhepunkt] en la naturaleza, y cada uno recibe este determinado estamento frente a los otros y a la naturaleza sólo por el hecho de estar en este determinado vínculo [...]. En el cuerpo orgánico cada parte conserva continuamente al todo $\mathrm{y}$, al conservarlo, es conservada ella misma; del mismo modo se relaciona el ciudadano con el Estado [...]: cada parte, o cada ciudadano, se conserva a sí mismo sólo en la posición determinada por el todo para él, así como por esto mismo el todo se conserva en sus partes: y precisamente porque el todo conserva cada parte en su posición determinada, vuelve sobre sí mismo y se conserva a sí mismo." (GA I, 4, 19 s. GNR; FDN 271 s.) ${ }^{23}$

La recuperación del organicismo clásico resignifica la posición del sujeto, que no es un átomo o grano de arena, sino un elemento más del tejido de relaciones. Además, no contribuye a la comunidad porque se lo aconseja el cálculo de su interés egoísta, sino 
que recibe del todo su situación correspondiente y a partir de allí colabora, de modo tal que su interés particular ya está inserto en el conjunto.

Ahora bien, la metáfora del árbol no recupera un rasgo constitutivo del organicismo clásico: los lugares estamentales naturales, jerárquicamente divididos y ordenados, y entre los cuales rige una diferencia en derechos y libertades. ${ }^{24}$ En una palabra, el desafío de Fichte consiste en conciliar el organicismo resucitado con la igualdad moderna; más aún, no sólo con la igualdad jurídico-formal, sino también con la socioeconómica. Con este interrogante nos encaminamos a la segunda sección del "Derecho político", titulada "De la legislación civil".

Al comienzo del $\S 18$ insiste en que el primer contrato a celebrar dentro del contrato estatal es el de la propiedad, y observa una diferencia entre el estado de naturaleza, donde el hombre queda supeditado a sus necesidades, y el Estado, donde se eleva a una condición superior. "La naturaleza ha determinado a los hombres [...] para la libertad, es decir, para la actividad." (GA I, 4, 21 GNR; FDN 274) Esta determinación condensa el presente y el futuro en la fórmula "poder vivir". Para que una persona permanezca en la organización social y su libertad resulte plenamente garantizada, sin degradarse al servilismo ni a la ociosidad, tiene que poder vivir de su actividad. ${ }^{25}$ La ramificación del Estado que nutre, sostiene y abraza a cada uno de sus miembros componentes, se revela aquí, siguiendo la metáfora del árbol, como la savia que mantiene la vitalidad del todo. La libertad, la propiedad o la seguridad, por ejemplo, son palabras vacías de contenido si la persona no puede vivir del propio trabajo. No refieren a la posesión de bienes, ni a los réditos del intercambio, tampoco al lujo; una persona es libre en la medida en que trabaja:

“Obtenemos así una determinación más precisa del uso de la libertad asignado con exclusividad a cada particular en el contrato de propiedad. Poder vivir es la propiedad absoluta e inalienable de todos los hombres. Hemos visto que les ha sido asignada con exclusividad una cierta esfera de objetos para un cierto uso. Pero el fin último de este uso es poder vivir. El logro de este fin está garantizado; éste es el espíritu del contrato de propiedad. El principio fundamental de toda constitución estatal racional es: todos deben poder vivir de su trabajo." (GA I, 4, 22 GNR; FDN 275)

El poder vivir de la propia actividad posiciona en condición de estricta igualdad a cada uno de los miembros del Estado. Aquel que no pueda vivir de su trabajo queda desvinculado jurídicamente, lo cual introduce una chispa de inseguridad directamente transferible a los restantes propietarios. Por lo tanto: "todos tienen que, según el derecho y a consecuencia del contrato social, dar de lo suyo hasta que él pueda vivir". (Ibíd.) La expropiación y repartición se justifica por la necesidad, y la asistencia al necesitado está intrínsecamente ligada al concepto de seguridad. Entonces, la seguridad recíproca no se agota en tener esto y aquello protegido de un eventual ataque, sino más bien se extiende al tener de qué vivir; y no sólo abarca la esfera de cada individuo, sino a su vez las relaciones por las cuales todos quedan afectados a la ruina o al lujo de sí o de otro. La protección se resignifica como asistencia social, y la economía como un asunto político.

Desde luego, la contrapartida de la pobreza que atenta contra el tejido social son aquellos que, gracias a la abundancia, permanecen ociosos. Así como no hay lugar para los primeros, tampoco hay lugar para estos últimos en el Estado racional-fichteano. Tal como lo vislumbraron Platón ${ }^{26}$ y Rousseau ${ }^{27}$, tenemos aquí los dos extremos que desintegran la sociedad. 
La pregunta fundamental que Fichte no aborda es si algunos podrían vivir del trabajo de otros, es decir, si cabe la posibilidad de que emerja en esta sociedad - como en Kant ${ }^{28}$ - un conjunto de asalariados. En primer lugar, cada uno debe expresar de qué va a vivir $y$, por ende, formar parte de un estamento social, que Fichte divide en tres: campesinos, industriales y comerciantes. En la subsistencia e interacción de cada uno de estos ramos, el Estado se instala racionalizando (con compensaciones, incentivos, restricciones, etc.) el espacio que los liberales defenderían como privado. Toda relación comercial está constituida por la acción o inacción del Estado. En segundo lugar, Fichte especifica: "La propiedad de los objetos" - digamos: los medios de producción - "es poseída por cada uno sólo en cuanto que los necesita para el ejercicio de su ocupación." (GA I, 4, 23 GNR; FDN 277) ${ }^{29}$ Por lo tanto, si no los necesita para su trabajo, no son suyos; no se puede ser propietario de objetos que uno mismo no utiliza. La ocupación se asume en primera persona. En este esquema hiperproductivo, delegar la actividad propia en otro sería como transferir la propia vida o libertad. Además, a nadie le convendría trabajar para otro si el Estado debe garantizarle su oficio. En suma, planteado el podervivir como un poder vivir de su propio trabajo, no hay lugar para los perezosos ni para los parásitos, que en última instancia son lo mismo. ${ }^{30}$

\section{7.}

Dos imágenes negativas permiten ilustrar el complejo malabarismo fichteano: de un lado, un poder soberano desgarrado de su constitución sociocomunitaria interna (esto es el despotismo, equivalente conceptual del dogmatismo); del otro, una armonía interindividual preestablecida y emergente de la sola dinámica de lo particular (el individualismo escéptico). A estos extremos se le puede oponer la siguiente paráfrasis irrecusable: no hay unidad sin multiplicidad, ni multiplicidad sin unidad. No hay Estado que resista el desgarramiento de su médula, la voluntad común, que se nutre de múltiples voluntades reunidas a través de la universalidad igualitaria; así como no hay intereses extrínsecos, planteados por fuera e independientemente de la comunidad, que logren realizar una armazón pacífica y confiable. Desde luego, caracterizada la búsqueda de Fichte bajo este doble rechazo, cabe esperar objeciones en uno y en otro sentido; por ejemplo: que las limitaciones al ejercicio de la soberanía encubren un derecho popular de resistencia, o que el intervencionismo estatal asfixia el desarrollo espontáneo de los individuos, etc.

51 Sucede que en la trabazón entre unidad y multiplicidad no resulta clara la asignación de funciones del tipo constituyente/constituido o determinante/determinado. En nuestro desarrollo hemos subrayado la prioridad del todo que posiciona a sus componentes, contrapesando las especulaciones problemáticas centradas en el individuo, y confiando que esa totalidad constituida opera según el leal saber y entender de la voluntad común. Pues, en última instancia, la comunidad - o su realización objetiva: la República - absorbe y disuelve a las partes, las unifica; y, sin embargo, en esa misma conformación de una totalidad libre sus miembros no pueden no ser libres.

52 Entonces, que el Estado posea una actividad propia significa que no se agota en esa figura negativa, restrictiva, de árbitro o guardián controlador, sino que conceptualmente reúne la actividad de sus miembros, y es él mismo esa actividad colectiva conformada por múltiples actividades particulares; tampoco significa que sea 
una insoportable carga contributiva, porque en este aspecto sólo succiona una porción de la actividad del contribuyente. Y que la libertad del individuo entre en relación dialéctica con el tejido social no significa que ella acabe donde comienza la del otro, como si éste fuese un obstáculo inhibidor o reductor de su libre expansión; significa, más bien, que la libertad de ambos existe gracias a un consenso fundamental que los aúna antes de limitarlos o posibilitarles la confrontación. El organicismo sociopolítico de Fichte descansa en el resguardo de una libertad total que, para efectivizarse a nivel particular, primero se revela como inserta en una unidad superior. En este sentido, para reconocerse individuo hay que reconocerse comunidad, y lo que define al otro define al sí-mismo; no cabe la asimetría. Es imposible la libertad en un esquema que no sea el de la igualdad de todas las partes. La unidad constitutiva pone y demarca la esfera de libertades, y de este modo vincula cada parte con cada parte, a tal punto que la organización se manifiesta en la actividad de cada uno de sus miembros.

La dificultad de fondo, más allá de los auxilios que la ética e incluso la religión podrían proporcionarle a la concepción jurídico-política, estriba en articular coherente y consistentemente la libertad en su instancia universal-comunitaria con la libertad en su instancia particular-individual. Desde la perspectiva de la organicidad vinculante, ambas instancias resultan inseparables, de modo que el vaciamiento de una es al mismo tiempo el vaciamiento de la otra. De ahí que la ficcionalidad del estado de naturaleza se traduzca en que el sujeto-átomo resulta ser una abstracción. El carácter heurístico de la misma empalma con la resignificación según la cual, esa libertad inicial que el individuo se auto-adjudica, en realidad es producto de la auto-organización comunitaria. Así, por ejemplo, la elección de un oficio o estamento, o la obediencia a la ley, contingentemente pueden arrojar un caso de discordia o de fisura entre la voluntad general y el querer del individuo. Pero, conceptualmente, el diseño fichteano presenta ambos momentos como dos caras de una misma moneda, de modo que en la actividad de uno está implicada la actividad de toda la comunidad.

\section{NOTAS}

1. Véase J. DотTI, El mundo de Juan Jacobo Rousseau. (reimp.) Bs. As. 1991: 35 ss.; G. Duso, "Patto sociale e forma politica", en: Il contratto sociale nella filosofia politica moderna. Milano 1998: 7-49; N. воввіо, “El modelo iusnaturalista", en: Thomas Hobbes. Trad. E. de Romaní. (reimp.) México 1995: $15 \mathrm{~s}$.

2. GA I, 3, 311-460 y I, 4, 1-165. Acompañamos los pasajes citados con la paginación de la versión en español FDN (véase el apartado "Siglas"). Las traducciones de los pasajes citados están basados en esta traducción y han sido modificados según como lo ha exigido cada caso.

3. En la Doctrina de la ciencia nova methodo (Wissenschaftslehre nova methodo), una reconstrucción de las lecciones de Fichte durante el mismo período de GNR a partir de anotaciones de distintos estudiantes, encontramos un apartado titulado "Algunas notas sobre el método sintético", contiguo al $\S 10$, donde Fichte presenta este proceder según tres variantes: partir de una contradicción y resolverla mediante lo aceptado; proponer una tarea principal y resolverla con proposiciones mediadoras; ir explicando progresivamente lo oscuro e indeterminado del punto 
inicial. En todos los casos, el significado de los elementos resulta comprensible una vez reunidos, y no por separado. Cf. GA IV, 2, 107 s. WLnm (DCnm 93-94).

4. J. L. Villacañas propone comprender esta obra como un doble movimiento intrínseco que atenta contra lo sistemático: por un lado, la comunidad moral determina al individuo; por otro lado, para garantizar el derecho originario Fichte apela a una concepción individualistahobbesiana. En esta tensión confluyen los más importantes comentadores (Siep, Verweyen, Schottky, Baumanns). Cf. J. L. VILLACAÑAS, "Fichte y el derecho natural: de la constitución social de la individualidad a la categoría de nación", estudio introductorio a FDN 22 ss. y 43 nota 53. En este aspecto, Villacañas al comienzo se inclina por la primacía del individuo (FDN 16-19), luego aclara que se requiere la comunidad (FDN 43-44), y finalmente hace surgir la primacía de la comunidad, que interpreta con la categoría de nación. (FDN 85 s. nota 124; 91 s. nota 140 y 94)

5. GA I, 1, 173 s. ZD. Trad. cast. RLP 14 s.

6. La relación entre teoría y práctica es uno de los tópicos fundamentales de la obra de Fichte. En GWL, al final del § 3, (GA I, 2, 282; FDC 33-34) sostiene que la práctica fundamenta y determina la teoría. La segunda parte de esta obra ( $\$ 4)$ está dedicada a la teoría y la tercera (\$§ 5-11) a la práctica. El $\S 5$ resulta importante para comprender la actividad objetiva como una modalidad de la actividad libre. En la WLnm Fichte también trata este tema (en especial §§ 6-7), pero desde otro ángulo. En "Representación de la alteridad y Derecho desde la aetas kantiana a Fichte" (en: M. Market y J. Rivera de Rosales (eds.) El inicio del idealismo alemán. Madrid 1995) F. Oncina Coves expone la relación entre teoría y práctica y caracteriza a FDN como "vaso comunicante" entre ambas y entre la GWL y la WLnm. (cf. 170-173)

7. Fichte sostiene que "en el ámbito de lo dado, y bajo la condición de que algo sea dado, el ser libre puede libremente dejar ese algo tal como es, o transformarlo, y entonces hacerlo tal como debe ser según su concepto de fin. Es libre de relacionar recíprocamente los elementos de lo múltiple que le está dado, de determinar unos a partir de otros, de adaptarlos unos con otros y de ensamblarlos para configurar un todo conforme a su fin." Y continúa en el párrafo siguiente: "Lo que no está modificado, cuando apenas es pensado por el ser racional e insertado en su mundo, precisamente por eso, porque no ha sido modificado, resulta modificado. La persona no ha modificado la cosa, en coherencia con el concepto de fin del todo al cual esta cosa determinada debe adaptarse, porque se adapta a esta figura natural que le es suya [...]. Su contención de una cierta actividad era ella misma actividad". (GA I, 3, 406 GNR; FDN 194-195)

8. Para Locke el derecho de propiedad se establece en el estado de naturaleza y el criterio que lo legitima es el trabajo. (cf. Segundo Tratado sobre el gobierno civil. Cap. 5, en especial § 27. (Trad. C. Mellizo) Bs. As., 1997) La sociedad civil, según Locke, tiene como finalidad fundamental proteger la propiedad en sentido amplio, que incluye la vida, la libertad y los bienes. (cf. cap. 7, § 87; cap. 9 , $\S \S 123-124)$ Además, la primacía de la propiedad se observa claramente en que para Locke ella define la pertenencia al Estado. (cf. §§ 119-121)

9. Dice Hobbes: “donde no se ha erigido un poder coactivo, es decir, donde no existe un Estado, no hay propiedad. Todos los hombres tienen derecho a todas las cosas, y por tanto donde no hay Estado, nada es injusto. Así que la naturaleza de la justicia consiste en la observancia de pactos válidos; ahora bien, la validez de los pactos no comienza sino con la constitución de un poder civil suficiente para compeler a los hombres a observarlos. Es entonces, también, cuando comienza la propiedad." (Leviatán, cap. XV; (Trad. Sánchez Sarto) Bs. As., (reimpr.) 1994: 119. Véase también cap. XVIII, punto 7: 146)

10. F. Oncina Coves traduce Macht por 'potencia'; sus razones las expone en FDN 429 nota 14.

11. Nos referimos a la famosa definición del personaje Trasímaco en La República de Platón (Libro I, 338c ss.; (Trad. A. Camarero) Bs. As., (reimpr.) 2008: 136 ss.), según la cual la justicia es el derecho del más fuerte. Rousseau presenta la hipótesis del pacto injusto, donde los ricos y fuertes someten a los débiles y pobres, desde el comienzo de la segunda parte - y, en especial, hacia la 
mitad de la misma - del Discurso sobre el origen de la desigualdad entre los hombres. (Trad. J. López y López. Bs. As. 1984: 101 y 114 s.)

12. El contrato "podría hacerse realidad sólo bajo la condición [...] de que cada uno tenga precisamente tanto poder como derecho. Esto sólo sucede [...] en una República. Por lo tanto, en modo alguno es posible una aplicación del derecho de coacción fuera de una República. A todo esto la coacción es conforme a derecho siempre sólo de un modo problemático, y ciertamente por esto la aplicación efectiva de la coacción, como si hubiera un derecho categórico a ejecutar la misma, es siempre injusta." (GA I, 3, 431 GNR; FDN 222)

13. Entre el último párrafo y el anterior citado, Fichte se plantea una disyunción excluyente: o bien se presupone una comunidad de seres morales perfectos y con absoluta confianza recíproca, o bien no. Es claro que desde el comienzo él sigue esta última línea que le garantiza sustancialidad a la política, así como es cierto que en otras ocasiones subordina el derecho a un ideal moral inalcanzable y a la vez rector del perfeccionamiento humano. (cf. GA I, 3, 23-68 BG) Sin embargo, en este pasaje que no citamos en el cuerpo principal de nuestro texto descarta de lleno esa posibilidad. Tras señalar que la coincidencia sería esporádica y tras caratularla como "el mayor azar de todos los azares", escribe: "Para un género de seres morales perfectos no se da ninguna ley jurídica. Que el hombre no pueda ser de este género, ya resulta claro, porque tiene que llegar a ser educado y educarse a sí mismo para la moralidad; porque el hombre no es moral por naturaleza, sino que debe hacerse moral principalmente por medio de su propio trabajo." (GA I, 3, 432 GNR; FDN 222) En última instancia, la hipotética bondad natural del hombre entraría en conflicto con su libertad. Si en la raíz de la elección existe una inclinación inmediata hacia el bien, como presupone el racionalismo dogmático, entonces la elección obedece a un mecanismo independiente del agente. Por eso Kant sostiene que una voluntad santa, a diferencia de la humana, no necesita del deber. (cf. Grundlegung der Metaphysik der Sitten. AA 04, 414; Fundamentación de la metafísica de las costumbres. (trad. M. García Morente) México 1996: 35; así como también Kritik der praktischen Vernunft. AA 05, 82; Crítica de la razón práctica. (Trad. M. García Morente) México 1996: 148) Por eso Schelling va a definir la auténtica libertad como la posibilidad radical de elegir, en igual medida, el bien o el mal. (cf. Investigaciones filosóficas sobre la esencia de la libertad humana. (Ed. bilingüe de H. Cortés y A. Leyte) Barcelona 1989: 150-151, en especial 178-179 y 190-191) A este y otros aspectos relacionados le hemos dedicado un trabajo: "Schelling. En el vientre de Dios", en: B. von Bilderling (comp.) Tras los pasos del mal. Una indagación en la filosofía moderna. Bs. As., 2009: 229-254.

14. Así comienza el $\S 16$ : "La tarea en que nos hemos detenido, que no hemos podido resolver y que esperamos resolver mediante el concepto de una República, era ésta: crear un poder, a través del cual entre personas que viven en comunidad [die bei einander leben] se pueda obtener por coacción el derecho o aquello que todas quieren necesariamente." (GA I, 3, 432 GNR; FDN 223)

15. En el párrafo siguiente dice: "La voluntad de un poder que ejerce el derecho de coacción no puede estar constituida así...”, en referencia a la subordinación de lo común a lo particularprivado; y continúa: "puesto que la subordinación de la voluntad privada bajo la común sólo se produce mediante el poder coactivo, y éste debe estar por encima de cualquier otro poder, tal subordinación al poder que coacciona no podría ser producida por ningún otro poder más que el suyo propio, lo cual es un contrasentido. Por lo tanto, aquella subordinación y concordancia no deben ser producidas en absoluto, sino que tienen que existir ya”. (GA I, 3, 433 GNR; FDN 223)

16. Véase como ejemplo de una tal interpretación J. L. Villacañas "Fichte y el derecho natural...", FDN 22.

17. "Si bien es cierto que en este caso su voluntad es la voluntad común a ellos, los opresores, [esta voluntad] no es, sin embargo, la voluntad común, porque los oprimidos no han cedido su voluntad. [De modo que] no es la voluntad común consagrada anteriormente como ley [...]. Por lo tanto, no es la voluntad de la ley, sino una voluntad dirigida contra la ley". (GA I, 3, 436 GNR; FDN 227). El argumento de Fichte contra la asociación opresora sería una rémora de la infalibilidad de 
la voluntad general rousseauniana (cf. El contrato social. Libro II, cap. III. (Trad. M. Villaverde) Barcelona 1993: 28-30)

18. "El poder coactivo, se ha dicho, tiene que ser tal que su autoconservación esté condicionada por su constante actividad y efectividad [Wirksamkeit]; por consiguiente, si está inactivo una vez, se aniquila por siempre. Su existencia en general depende de su existencia o exteriorización en cada caso particular". (GA I, 3, 437; FDN 228)

19. Cf. F. ONCINA COVES, "El iusnaturalismo agónico: la teoría fichteana del contrato", en: V. López Domínguez (ed.) Fichte 200 años después. Madrid 1996: 92.

20. El texto prosigue así: "La razón es una, y su exposición en el mundo sensible también es sólo una; la humanidad es un todo único, organizado y organizador de la razón. Ella fue separada en múltiples miembros independientes unos de otros, y ahora la constitución natural del Estado supera provisoriamente esa independencia, y funde cantidades particulares en un todo, hasta que la eticidad transforme en una a la especie entera." (GA I, 4, 14 GNR; FDN 267) Este cosmopolitismo fichteano, donde el Estado sería apenas un paso intermedio para la unidad mundial, se condice con su posición de 1794 en Algunas lecciones sobre el destino del sabio, especialmente en la "Segunda lección"; (cf. GA I, 3, 37-41 BG; DS 74-75) y también se condice con la reseña que hizo Fichte en 1796 de Para la paz perpetua de Kant. (GA I, 3, 221-228; trad. F. Oncina Coves, en Daímon. Revista de Filosofía, Murcia, no 9 (1994): 373-381) Sin embargo, en El Estado comercial cerrado (1800) (trad. J. Franco Barrio, Madrid 1991) Fichte propone considerar al Estado como una totalidad autosubsistente, que así como se vuelve autónoma en el plano jurídico y político, tiene que independizarse y cerrarse en el plano comercial. Ya en la "Dedicatoria" denuncia que Europa, en especial, los países más favorecidos, pero indirectamente también los demás, se apropia de trabajo y bienes de otros Estados, y por eso se excusan de implementar este proyecto y lo declaran irrealizable. (cf. GA I, 7, 43-44) Es decir, el comercio internacional - y esta premisa recorre todo el texto - degenera en una guerra donde hay vencedores y vencidos, opresores y oprimidos, y no en una conciliación genérica. Así, por ejemplo, en el Libro II, cap. IV, cuando analiza el empobrecimiento de una nación, sostiene que el Estado finalmente se vende, pierde su autonomía y se anexa como provincia de otro. (cf. GA I, 7, 103). En este sentido, el espacio universal interestatal es el de una guerra de todos contra todos, (cf. GA I, 7, 106) donde el perjuicio de los competidores es sinónimo del rédito propio. En el libro III, cap. I Fichte declara que el cierre comercial del Estado se corresponde con el único sistema político deducido de la razón. (cf. GA I, 7, 114). Agrega luego en el cap. II que no se trata de una renuncia ni de una modesta limitación, y que a lo sumo la expansión del Estado se explica por un completarse, por un hacerse autosubsistente, hasta finalmente cerrarse sobre sí. (cf. GA I, 7, 116) En las últimas páginas parece volver sobre sus pasos y se pregunta sobre una cultura universal, a lo cual responde: "No hay nada que supere puramente toda la diferencia de situaciones y de los pueblos, y que pertenezca sólo y exclusivamente a lo humano como tal y no al ciudadano." (GA I, 7 141). La única excepción es la ciencia, el conocimiento, que los Estados han de promover, siempre con la mirada puesta en el propio mejoramiento. Véase también J. L. VILLACAÑAS “Fichte, el Estado y el derecho internacional”, en: Fichte 200 años después: 107 s.

21. "El individuo, a consecuencia del contrato de reunión, deviene parte de un todo organizado y, según esto, se funde con el mismo en unidad. ¿Está entrelazado según todo su ser y toda su esencia, o sólo en parte, de modo que considerado desde otra perspectiva permanece todavía libre e independiente?" (GA I, 4, 15 GNR; FDN 268) Fichte responde en el párrafo siguiente: "Cada uno da al cuerpo protector su contribución [...]. Pero él mismo no se da totalmente, ni da totalmente lo que pertenece a él." (GA I, 4, 16 GNR; FDN 268-269) Rousseau pareciera decir algo similar en El contrato social, Libro II, cap. IV; (ed. cit. 30-31) de todos modos, la determinación de lo que la comunidad necesita de sus miembros recae en el soberano.

22. J. J. Rousseau, El contrato social, Libro I, capítulos VI, VIII y IX. En el cap. IX, (ed. cit. 22) y en el Libro II, cap. IV, (ed. cit. 33) alude a la ventaja que suscita el pasaje del estado de naturaleza al 
Estado, donde las posesiones son asumidas y repartidas por el Estado, y así reconocidas y aseguradas como propiedades. Fichte vuelve sobre este punto en El Estado comercial cerrado, Libro I, cap. I: “En oposición a esta opinión [según la cual el Estado sólo tiene que mantener y proteger los derechos personales y las propiedades de cada uno], yo diría que forma parte de la destinación [Bestimmung] del Estado, primero dar a cada uno lo suyo, primero ponerlo en su propiedad, y sólo después también protegerlo." (GA I, 7, 53; trad. 16)

23. Además del organicismo clásico, Fichte debiera reconocer en Rousseau un antecedente de su propuesta. Véase, por ejemplo, en el Libro I, cap. VII, sobre el compromiso recíproco de los individuos y para con el Estado, (El contrato social, ed. cit. 17), sobre el cuerpo social (17-18); en el Libro II, cap. II: sobre la indivisibilidad de la soberanía, donde pone el ejemplo del niño despedazado (27), así como también cap. IV. (30-31 y 33) "Los compromisos [...] son mutuos, y su naturaleza es tal que, al cumplirlos, no se puede trabajar para los demás sin trabajar también para uno mismo." (31) En Algunas lecciones sobre el destino del sabio, Tercera lección, Fichte emula a Rousseau, al describir el vínculo [Verbindung] social de la siguiente manera: "nadie puede trabajar para sí mismo sin trabajar para todos los otros, y nadie puede trabajar para los otros sin trabajar igualmente para sí mismo." (GA, I, 3, 49; DS 102-103)

24. Fichte expone claramente esta diferenciación en Die Staatslehre (La Doctrina del Estado), lecciones que brinda en la Universidad de Berlín en 1813 y que fueron publicadas póstumamente. Tras analizar el mundo antiguo, concluye que el Estado y su constitución responden a un "absoluto ordenamiento divino". (FW IV, 500) El desacople fundamental entre las relaciones recíprocas y el derecho Fichte lo encuentra en la desigualdad entre hombres libres y esclavos. (FW IV, 507) El mundo moderno, en cambio, ofrece una profunda transformación -metafísica, religiosa, y por cierto política-, porque introduce "un Dios, cuya voluntad no se dirige hacia un ser dado, sino hacia lo que debe ser como tal, hacia un devenir en la eternidad toda, y lo que debe ser no se dirige a cualquier libre arbitrio de Dios, sino consecuentemente a su esencia interna, cuya voluntad [...] pone absolutamente fuera de sí la libertad absoluta [...]. Sólo en la forma de la libertad Dios es visible". (FW IV, 521-522) Por lo tanto, el mundo moderno quiebra con la desigualdad divino-natural, y establece como principio fundamental en la relación entre Dios y los hombres la libertad de todos. (cf. FW IV 529)

25. "El fin supremo y universal de toda actividad libre es, por lo tanto, poder vivir. Cada uno tiene este fin, y está garantizado por cuanto está garantizada la libertad en general. Sin su logro no sería posible en absoluto la libertad y la permanencia de la persona." (GA I, 4, 22 GNR; FDN 275) A diferencia de BG, donde el individuo elige el estamento del cual formará parte, (cf. GA I, 3 , 46 s. BG; trad. 94 s.) aquí y en El Estado comercial cerrado (cf. GA I, 7, 60-61; trad. 27-29) esa libertad debe consensuarse con la visión soberana.

26. En La República, Libro IV, apartado II, 421d-422a, ed. cit. 282-283, Platón trata el caso del alfarero que, tanto enriqueciéndose como empobreciéndose, degrada su trabajo, y apuntala que los guardianes del estamento superior "deben impedir" ambos extremos, pero sin indicar cómo.

27. J. J. Rousseau, en El contrato social, Libro I, cap. IX, ed. cit. 23 nota 5, dice: “...el estado social sólo es ventajoso para los hombres si todos poseen algo y ninguno de ellos demasiado". Y en el Libro II, cap. XI, 51: “...que ningún ciudadano sea suficientemente opulento como para comprar a otro, ni ninguno tan pobre como para ser obligado a venderse".

28. Según Kant ciudadano es quien "tenga alguna propiedad [...] que lo mantenga; es decir, que en los casos que tenga que ganarse la vida por medio de otros lo haga sólo por enajenación de lo que es suyo y no por concesión de sus fuerzas para que otro haga uso de ellas". ("Acerca del refrán: «Lo que es cierto en teoría, para nada sirve en la práctica»", en Filosofía de la historia. (Trad. E. Estiú) La Plata 2004: 117) En nota a pie de página Kant incluye explícitamente como propietarios a artesanos y comerciantes, y excluye a los asalariados. Unas líneas más abajo, Kant desestima la pregunta rousseauniana sobre el origen de la desigualdad de propiedades que dio lugar a que algunos "se han visto reducidos a servir a otros para poder vivir". (118) 
29. En El Estado comercial cerrado, Libro I, cap. VII, (cf. GA I, 7, 84 ss.) Fichte desarrolla su teoría de la propiedad y sostiene que el "error fundamental" de las otras teorías consiste en concentrarse en las cosas, y no en el uso, esto es, en la actividad aplicada sobre el objeto. Según Fichte a diferencia del derecho a la propiedad que no es posible sin suponer una actividad que se apropie de la cosa en cuestión, "el derecho exclusivo a la actividad sucede sin [que haya] propiedad de alguna cosa; [éste es] el derecho exclusivo, mencionado más arriba, a ejercer un oficio o una actividad comercial, en el cual no se debe atender en absoluto a la propiedad, lo cual es accidental, de herramientas $\mathrm{u}$ objetos de este [u otro] oficio, que precisamente tampoco son propiedad del trabajador, sino que le han podido ser prestados o suministrados." (GA I, 7, 88; trad. 74) Para que no queden dudas, luego detalla con un ejemplo la estricta igualdad de la distribución de propiedades: si hay cien campesinos, el terreno debe dividirse en cien parcelas. (cf. GA I, 7, 88; trad. 75)

30. Dice Fichte: "la fuente de todos los vicios es la pereza". (GA I, 3, 66 BG; DS 144-145) Luego critica la lógica de gozar más haciendo menos, tan propia del capitalismo. En la nota 24 de la edición en español de BG (DS 160) los traductores aluden a un pasaje similar de SSL (cf. SisEt 242)

\section{RESÚMENES}

In Fichte's GNR various concepts of iusnaturalism appear (natural rights, pact, State); but, what do those concepts mean? A first problem of interpretation is synthetic method, according to which each element must be understood in relation to the other elements, and must also in the whole of their relations (I). The original right (II) and right to coercion (III), which would be equivalent to natural condition, are not the ground of State, but presentation of irresolvable conflict which shows the need to generate the State. Fichte says: "the State itself becomes the natural state of man", because the natural condition is a fiction to be conceptualized in the rational State. Those rights can't subsist out of the State. As a unity of multiple subjects, the State does not arise from the conjunction or concordance among themselves, but the unity is previous, because it identifies the multiple subjects in a common desire (IV). At this point Fichte has to explain how the totality is generated, that it isn't a whole, i.e., the communitarian organicism of common will as shown in the State $(\mathrm{V})$. This equalitarian organicism is based on the fact that each particular subject can live off his labor (VI). Therefore, Fichte's State consideres the field of trade relations as his own (VII), and this conception does not fall into liberalism or into authoritarianism.

\section{ÍNDICE}

Keywords: natural condition, originals rights and right of coercion, foundation of State, common want, totality, can-live off his labor 
AUTOR

MARIANO GAUDIO

Buenos Aires 